\title{
Effect of continuous renal replacement therapy on kidney injury molecule-1 and neutrophil gelatinase-associated lipocalin in patients with septic acute kidney injury
}

\author{
YIMING SHAO $^{1 *}$, YINQIANG FAN ${ }^{1 *}$, YULIU XIE $^{1}$, LU YIN $^{1}$, YUANLI ZHANG ${ }^{1}$, LIEHUA DENG $^{1}$, \\ XIAOCONG SUN $^{1}$, XIN SHAO $^{1}$, XINZHANG TAN $^{1}$, JUNBING HE $^{1}$ and SHIMAN ZHAO ${ }^{2}$ \\ ${ }^{1}$ Intensive Care Unit; ${ }^{2}$ Department of Traditional Chinese Medicine, \\ The Affiliated Hospital of Guangdong Medical University, Zhanjiang, Guangdong 524001, P.R. China
}

Received November 9, 2015; Accepted January 13, 2017

DOI: $10.3892 / e t m .2017 .4436$

\begin{abstract}
Kidney injury molecule-1 (Kim-1) and neutrophil gelatinase-associated lipocalin (NGAL) have been investigated as biomarkers for acute kidney injury (AKI). However, they are seldom investigated in patients with septic AKI treated with continuous renal replacement therapy (CRRT). The aim of the present study was to investigate the therapeutic effectiveness and possible mechanisms of CRRT in septic AKI by observing the changes in Kim-1 and NGAL levels. A group of 38 patients with septic AKI was randomly divided into the conventional drug treatment group (group A) and the CRRT group (group B). All patients were treated with standard antisepsis agents, and group B was additionally submitted to CRRT for $24 \mathrm{~h}$. The levels of Kim-1 and NGAL in serum, urine and the ultrafiltrate of CRRT were measured prior to and at 12,24 , and $48 \mathrm{~h}$ after treatment. In group A, urinary Kim-1 (uKim-1) levels at 12, 24 and 48 h were lower than prior to treatment $(\mathrm{P}<0.05)$, whereas urinary NGAL (uNGAL) showed no difference among the various time points ( $\mathrm{P}>0.05)$. In group B, uKim-1 was decreased at 24 and $48 \mathrm{~h}$ compared with before treatment (all $\mathrm{P}<0.05)$, whereas uNGAL
\end{abstract}

Correspondence to: Professor Yiming Shao, Intensive Care Unit, The Affiliated Hospital of Guangdong Medical University, 57 Renmin South Street, Xiashan, Zhanjiang, Guangdong 524001, P.R. China

E-mail: yimingshao_gmc@126.com

Professor Shiman Zhao, Department of Traditional Chinese Medicine, The Affiliated Hospital of Guangdong Medical University, 57 Renmin South Street, Xiashan, Zhanjiang, Guangdong 524001, P.R. China

E-mail: shimanzhao@126.com

*Contributed equally

Key words: sepsis, acute kidney injury, kidney injury molecule-1, neutrophil gelatinase-associated lipocalin, continuous renal replacement therapy, mechanisms was decreased at $48 \mathrm{~h}(\mathrm{P}<0.05)$. Serum Kim-1 did not change with time in groups $\mathrm{A}$ and $\mathrm{B}(\mathrm{P}>0.05)$, whereas serum NGAL was increased after treatment in group $\mathrm{A}(\mathrm{P}<0.05)$ but did not change in group B $(\mathrm{P}>0.05)$. Kim-1 and NGAL were not detected in the ultrafiltrate of CRRT. uKim-1 and UNGAL decreased significantly after CRRT, and therefore may be used to reflect the change of renal function during CRRT and to evaluate the therapeutic effectiveness of the method.

\section{Introduction}

Acute kidney injury (AKI) is one of the most common complications observed in patients in the intensive care unit (ICU). In a large multicenter cohort study, AKI was estimated to occur in $42.7 \%$ of all patients admitted to the ICU, and $~ 30.6 \%$ of these AKI cases were caused by sepsis (1). Sepsis is a leading contributing factor to AKI development in critically ill patients. In a previous study, it was found that the fatality rate of severe sepsis or septic shock was $55.2 \%$, which increased to $67.3 \%$ when associated with AKI; septic AKI was an independent risk factor for prognosis in hospitalized patients with sepsis (2).

In recent years, continuous renal replacement therapy (CRRT) has been widely used in critically ill patients, and $\sim 30 \%$ of septic AKI cases require CRRT (3). However, the mechanism of action of CRRT for septic AKI has been not fully clarified, and its optimal timing, dosing, and efficacy have been controversial. The optimal CRRT and renal recovery procedures are difficult to determine because of the lack of reliable biomarkers for the evaluation of renal injury during CRRT. Currently, neutrophil gelatinase-associated lipocalin (NGAL), interleukin (IL)-18, cystatin C and kidney injury molecule 1 (Kim-1) may be the most promising biomarkers (4-8). Several studies have established the potential clinical role of Kim-1 and NGAL as predictive biomarkers for AKI (9-12).

Although Kim-1 and NGAL are predictive biomarkers for AKI in a variety of clinical contexts, including intensive care, cardiac surgery and renal transplantation (13-16), they are seldom investigated in patients with septic AKI treated with CRRT. Therefore, the present single-center randomized controlled study was conducted to evaluate the therapeutic 
efficacy of CRRT and observe its effect on Kim-1 and NGAL levels in patients with septic AKI, in order to provide evidence-based recommendations on the clinical applications of CRRT for septic AKI.

\section{Materials and methods}

Patients. Patients with septic AKI were divided into the conventional drug treatment group (group A) and the CRRT group (group B) using a random data table. This study was conducted in accordance with the Declaration of Helsinki, and with approval from the Ethics Committee of Guangdong Medical University (Zhanjiang, China). Written informed consent was obtained from all participants.

All enrolled patients were $>18$ years old, with septic AKI, admitted to the ICU and required standard antisepsis treatment according to 2012 Surviving Sepsis Campaign guidelines (17). All patients were instructed to avoid using nephrotoxic drugs during the study. Sepsis was defined as the presence of both infection and a systemic inflammatory response (SIRS). SIRS was considered to be present when patients had more than one of the following clinical findings (18): i) Body temperature (T) $>38$ or $<36^{\circ} \mathrm{C}$, ii) heart rate $>90$ beats $/ \mathrm{min}$, iii) hyperventilation evidenced by a respiratory rate of $>20 / \mathrm{min}$ or $\mathrm{PaCO}_{2}$ $<32 \mathrm{~mm} \mathrm{Hg}$, and iv) white blood cell count (WBC) $>12,000$ or $<4,000$ cells $/ \mu 1$.

The diagnosis of AKI was based on the above criteria and on the presence of at least one of the following (19): An abrupt (within $48 \mathrm{~h}$ ) reduction in kidney function defined as an absolute increase in serum creatinine $(\mathrm{sCr})$ of $\geq 0.3 \mathrm{mg} / \mathrm{dl}$ ( $\geq 26.4 \mu \mathrm{mol} / \mathrm{l}$ ), a percentage increase in $\mathrm{sCr}$ of $\geq 50 \%$ (1.5-fold from baseline), or a reduction in urine output (documented oliguria of $<0.5 \mathrm{ml} / \mathrm{kg} / \mathrm{h}$ urine output for $>6 \mathrm{~h}$ ).

The exclusion criteria were the presence of a malignant tumor, pregnancy in female patients, chronic renal insufficiency, use of nephrotoxic drugs, or receiving any kind of renal replacement therapy prior to being admitted to the ICU, or a change of the treatment plan being necessary due to a change in the patient's condition, or refusal to take part in this study while it was ongoing.

Healthy volunteers. A group of 20 healthy volunteers was included in the study as the control group (group C).

CRRT protocol. All patients in the CRRT group were treated with continuous venous-venous hemofiltration $(\mathrm{CVVH})$ for $24 \mathrm{~h}$. If the pipe or filter became clogged, it could immediately be replaced with a new one for continuation of the treatment. However, data obtained when clogged filters were present were excluded. Central venous access with $12-\mathrm{FR}$ 20-cm catheters (Double lumen 801407, SCW Medicath Ltd., Shenzhen, China) was used. Two AQUARIUS machines (Edwards Lifesciences Corp., Irvine, CA, USA) were used for CRRT, with polysulfone filters (AV600s; Fresenius SE \& Co., Bad Homburg, Germany). The replacement fluid consisted of 3,000 $\mathrm{ml}$ physiological saline, 1,000 ml water for injection, $100 \mathrm{ml} \mathrm{10 \%} \mathrm{glucose,} 20 \mathrm{ml} \mathrm{5 \%}$ calcium chloride, $10 \mathrm{ml} 10 \%$ potassium chloride, $5 \mathrm{ml} 10 \%$ sodium chloride, and $3 \mathrm{ml} 25 \%$ magnesium sulfate; the solution was infused into the CRRT circuit using a sterile intravenous nutrition bag. A 5\% bicarbonate solution was infused into the patients through another central venous catheter. The replacement fluid formulations and sodium bicarbonate infusion were changed according to arterial blood gas level, which was checked every $2 \mathrm{~h}$. CRRT was initiated with a blood flow rate of $100 \mathrm{ml} / \mathrm{min}$, which was gradually increased to $180 \mathrm{ml} / \mathrm{min}$ and maintained at $180-220 \mathrm{ml} / \mathrm{min}$. Anticoagulation was performed with unfractionated heparin $(2 \mathrm{ml} ; 12,500$ IU. H31022051; Shanghai first biochemical pharmaceutical Co. Ltd. Shanghai, China) in patients with low risk of hemorrhage. The heparin was replaced with $0.9 \%$ nature saline if the patients had a high risk of hemorrhage. The replacement fluid was delivered into the extracorporeal circuit at a predilution $(3,000 \mathrm{ml} / \mathrm{h})$ to postdilution $(1,000 \mathrm{ml} / \mathrm{h})$ ratio of $3: 1$.

Dosing of antibiotics and the nutrition of all patients were adjusted according to the clearance of CRRT, apparent volume of distribution, creatinine clearance, protein binding rate and glomerular filtration rate during the treatment period (20).

The CONSORT 2010 flow diagram for the study process is presented in Fig. 1.

Measured variables. The sCr, serum Kim-1 (sKim-1), urinary Kim-1 (uKim-1), serum NGAL (sNGAL) and urinary NGAL (uNGAL) levels were measured prior to and at 12, 24 and $48 \mathrm{~h}$ after treatment. Moreover, Kim-1 and NGAL in the ultrafiltrate of CRRT were also measured in group B. The clinical baseline data collected included T, WBC, neutrophilic granulocyte ratio $(\mathrm{NE})$, procalcitonin $(\mathrm{PCT})$ and arterial blood lactic acid (Lac). Acute Physiology and Chronicity Health Evaluation II (APACHE II) scores (21) were assessed concurrently, and the 28-day mortality was also recorded. Kim-1 and NGAL were measured using an enzyme-linked immunosorbent assay (ELISA) device supplied by Bio-Swamp (Shanghai, China).

ELISA. ELISAs were performed to measure the sKim-1, uKim-1, sNGAL, and uNGAL levels. In brief, sKim-1, uKim-1, sNGAL and UNGAL were measured using a specific ELISA kit for each marker (Human NGAL ELISA Kit, HM10120; Human Kim-1 ELISA Kit, HM10892; both R\&D Systems, Inc., Minneapolis, MN, USA) according to the manufacturer's instructions. The absorbance of each sample was read at $450 \mathrm{~nm}$ with a microplate reader, and the final cytokine levels were determined in accordance with the standard curve.

Statistical analysis. Statistical analysis was performed using SPSS 17.0 software (SPSS, Inc., Chicago, IL, USA). All data are presented as mean \pm standard deviations. Continuous variables were compared using student t-tests, and comparison between groups to select unpaired t-tests, within group comparison using one-way analysis of variance and categorical parameters were compared using $\chi^{2}$ tests. Patient survival was analyzed with the Kaplan-Meier method. $\mathrm{P}<0.05$ was considered to indicate a statistically significant difference.

\section{Results}

General clinical data. A total of 38 eligible patients with septic AKI in the ICU were enrolled into the study between March 2012 and December 2012. Of these, 17 patients were assigned 


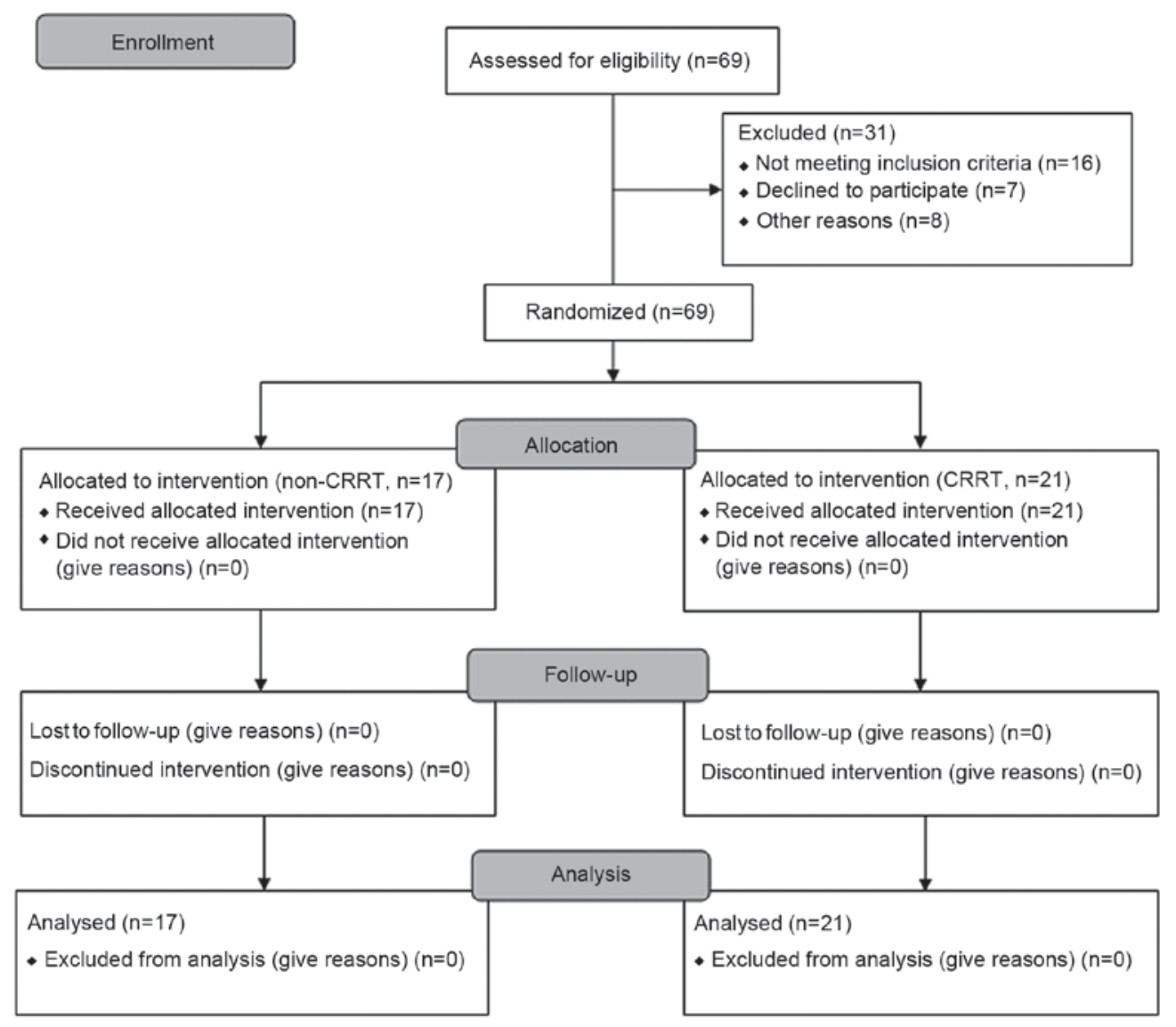

Figure 1. CONSORT 2010 flow diagram for the study. CRRT, continuous renal replacement therapy.

to the conventional drug treatment group and 21 patients to the CRRT group. In the control group (group $\mathrm{C}$ ), the $\mathrm{T}$, WBC, NE, PCT, sCr, blood urea nitrogen and Lac levels, as well as the APACHE II scores were significantly lower than those in groups A and B $(\mathrm{P}<0.01$; Table I). All initial baseline characteristics including Kim-1 and NGAL were similar between groups A and B (Table II).

Changes of Kim-1, NGAL, and sCr Kim-1. In group A, uKim-1 at 12,24 and $48 \mathrm{~h}$ was significantly lower compared with that at $0 \mathrm{~h}(\mathrm{P}<0.05)$. uKim-1 was decreased significantly at 24 and $48 \mathrm{~h}$ compared with that at $0 \mathrm{~h}($ all $\mathrm{P}<0.05)$ in group $\mathrm{B}$. There were no significant differences between groups $\mathrm{A}$ and $\mathrm{B}$ in uKim-1 ( $\mathrm{P}>0.05$; Table III and Fig. 2A). sKim-1 showed no significant difference among all time points prior to and following treatment in groups $\mathrm{A}$ and $\mathrm{B}(\mathrm{P}>0.05)$; however, expression levels were significantly decreased at $0,12,24$ and $48 \mathrm{~h}$ in group $\mathrm{B}$ compared with group A (all $\mathrm{P}<0.05$; Table III and Fig. 2B). Kim-1 was not detected in ultra-filtrate.

NGAL. uNGAL showed no significant difference among the time points prior to and following treatment in group A ( $\mathrm{P}>0.05)$; however, expression levels were significantly lower at $48 \mathrm{~h}$ than that at $0 \mathrm{~h}$ in group $\mathrm{B}(\mathrm{P}<0.05)$, and also significantly decreased at $0,12,24$ and $48 \mathrm{~h}$ in group $\mathrm{B}$ compared with group $\mathrm{A}(\mathrm{P}<0.05$; Table III and Fig. $2 \mathrm{C})$. sNGAL in group A was significantly increased at 12,24 and $48 \mathrm{~h}$ compared with $0 \mathrm{~h}$, and expression levels at $48 \mathrm{~h}$ were significantly lower compared with $12 \mathrm{~h}($ all $\mathrm{P}<0.05)$, but remained stable at all-time points in group $\mathrm{B}(\mathrm{P}>0.05)$. sNGAL in group $\mathrm{B}$ was significantly decreased at 12,24 and $48 \mathrm{~h}$ compared with that in group A (all $\mathrm{P}<0.05$; Table III and Fig. 2D). NGAL was not detected in ultra-filtrate.

$s C r$. sCr was significantly increased at 12 and 48 h compared with at $0 \mathrm{~h}$ in group $\mathrm{A}(\mathrm{P}<0.05)$; however, levels were decreased significantly at 24 and 48 h compared with 0 and $12 \mathrm{~h}$ in group $\mathrm{B}$ (all $\mathrm{P}<0.05)$. $\mathrm{sCr}$ in group $\mathrm{B}$ was decreased significantly compared with that in group $\mathrm{A}$ at the three time points after treatment $(\mathrm{P}<0.05$; Table III and Fig. $2 \mathrm{E})$.

Infectious process and 28-day mortality. In group A and B, the temperature was significantly decreased at 24 and $48 \mathrm{~h}$ compared with that at $0 \mathrm{~h}(\mathrm{P}<0.05)$. In group $\mathrm{B}, \mathrm{Lac}$ and PCT were significantly decreased at 24 and $48 \mathrm{~h}$ compared with $0 \mathrm{~h}$; however, in group A, Lac and PCT were significantly increased at the same time points compared with $0 \mathrm{~h}$, respectively. WBC was significantly increased at $12 \mathrm{~h}$ compared with that at $0 \mathrm{~h}$ in group $\mathrm{A}$, but not in group B. Furthermore, the APACHE II score was significantly increased at 24 and $48 \mathrm{~h}$ compared with that at 0 and $12 \mathrm{~h}$ in group $\mathrm{A}$; however, the scores were significantly decreased in group B at the same time points $(\mathrm{P}<0.05)$. Temperature, WBC, NE, Lac, PCT and APACHE II scores were significantly decreased after CRRT in group B at 24 and $48 \mathrm{~h}$ compared with that at the same time point in group A (all $\mathrm{P}<0.05$; Table IV). The results showed 
Table I. General clinical data and APACHE II score for all patients.

\begin{tabular}{|c|c|c|c|}
\hline Items & Group A & Group B & Group C \\
\hline Male sex (n) & 9 & 11 & 10 \\
\hline Female sex (n) & 8 & 10 & 10 \\
\hline Age (years) & $50.22 \pm 20.06$ & $48.95 \pm 18.60$ & $47.45 \pm 18.80$ \\
\hline Weight (kg) & $62.76 \pm 9.21$ & $64.23 \pm 9.45$ & $63.41 \pm 8.86$ \\
\hline $\mathrm{T}\left({ }^{\circ} \mathrm{C}\right)$ & $39.42 \pm 0.46^{\mathrm{a}}$ & $39.21 \pm 0.45^{\mathrm{a}}$ & $36.21 \pm 0.14$ \\
\hline WBC (x109/1) & $14.84 \pm 3.22^{\mathrm{a}}$ & $15.56 \pm 3.17^{\mathrm{a}}$ & $4.47 \pm 0.90$ \\
\hline $\mathrm{NE}(\%)$ & $85.38 \pm 5.76^{\mathrm{a}}$ & $85.07 \pm 5.90^{\mathrm{a}}$ & $58.97 \pm 3.47$ \\
\hline PCT (ng/ml) & $6.08 \pm 2.15^{\mathrm{a}}$ & $6.12 \pm 2.08^{\mathrm{a}}$ & $0.16 \pm 0.05$ \\
\hline BUN (mmol/l) & $13.01 \pm 8.07^{\mathrm{a}}$ & $15.20 \pm 7.64^{\mathrm{a}}$ & $5.22 \pm 2.43$ \\
\hline $\mathrm{sCr}(\mu \mathrm{mol} / \mathrm{l})$ & $176 \pm 18^{a}$ & $170 \pm 24^{\mathrm{a}}$ & $72 \pm 16$ \\
\hline $\mathrm{Lac}(\mathrm{mmol} / \mathrm{l})$ & $6.74 \pm 2.01^{\mathrm{a}}$ & $6.27 \pm 1.59^{\mathrm{a}}$ & $0.52 \pm 0.07$ \\
\hline APACHE II score & $13.89 \pm 2.03^{\mathrm{a}}$ & $14.86 \pm 1.81^{\mathrm{a}}$ & NS \\
\hline \multicolumn{4}{|l|}{ Infection state (n) } \\
\hline Lung & 4 & 6 & - \\
\hline Abdominal $^{\mathrm{b}}$ & 9 & 11 & - \\
\hline Biliary tract & 4 & 2 & - \\
\hline Other parts ${ }^{\mathrm{c}}$ & 1 & 1 & - \\
\hline
\end{tabular}

${ }^{\mathrm{a}} \mathrm{P}<0.01$ vs. group $\mathrm{C}$; ${ }^{\mathrm{b}}$ abdominal infection (including postoperative infection of the gastrointestinal tract, acute pancreatitis and acute peritonitis caused by gastrointestinal perforation); ' other parts (including extremities and urinary tract infection). NS, no score; Group A, septic acute kidney injury with conventional drug treatment; group B, septic acute kidney injury with continuous renal replacement therapy; group C, healthy control; T, body temperature; WBC, white blood cell count; NE, neutrophilic granulocyte ratio; PCT, procalcitonin; BUN, blood urea nitrogen; sCr, serum creatinine; Lac, arterial blood lactic acid; APACHE II, acute physiology and chronicity health evaluation II.

Table II. Levels of sKim-1, uKim-1, sNGAL and uNGAL prior to treatment.

\begin{tabular}{lccc}
\hline Variable & Group A & Group B & Group C \\
\hline $\mathrm{n}$ & 17 & 21 & 20 \\
$\mathrm{uKim}-1(\mathrm{pg} / \mathrm{ml})$ & $1,154 \pm 21^{\mathrm{a}}$ & $1,145 \pm 56^{\mathrm{a}}$ & $580 \pm 40$ \\
$\mathrm{sKim}-1(\mathrm{pg} / \mathrm{ml})$ & $518 \pm 167^{\mathrm{a}}$ & $410 \pm 31^{\mathrm{a}}$ & $290 \pm 30$ \\
$\mathrm{uNGAL}(\mathrm{pg} / \mathrm{ml})$ & $3,638 \pm 179^{\mathrm{a}}$ & $3,449 \pm 362^{\mathrm{a}}$ & $1,720 \pm 40$ \\
sNGAL $(\mathrm{pg} / \mathrm{ml})$ & $1,333 \pm 150^{\mathrm{a}}$ & $1,318 \pm 172^{\mathrm{a}}$ & $950 \pm 10$ \\
\hline
\end{tabular}

${ }^{\text {aP }}<0.01$ vs. group C. Group A, septic acute kidney injury with conventional drug treatment; group B, septic acute kidney injury with continuous renal replacement therapy; group C, healthy control; sKim-1, serum urinary kidney injury molecule 1; uKim-1, urinary kidney injury molecule 1; sNGAL, serum neutrophil gelatinase-associated lipocalin; uNGAL, urinary neutrophil gelatinase-associated lipocalin.

Table III. Levels of Kim-1, NGAL and sCr in patients with septic acute kidney injury before and after treatment.

\begin{tabular}{|c|c|c|c|c|c|c|c|c|}
\hline \multirow[b]{2}{*}{ Biomarker } & \multicolumn{4}{|c|}{ Group A $(n=17)$} & \multicolumn{4}{|c|}{ Group B $(n=21)$} \\
\hline & $0 \mathrm{~h}$ & $12 \mathrm{~h}$ & $24 \mathrm{~h}$ & $48 \mathrm{~h}$ & $0 \mathrm{~h}$ & $12 \mathrm{~h}$ & $24 \mathrm{~h}$ & $48 \mathrm{~h}$ \\
\hline uKim-1 (pg/ml) & $1,154 \pm 21$ & $1,120 \pm 26^{\mathrm{a}}$ & $1,100 \pm 33^{\mathrm{a}}$ & $1,104 \pm 43^{\mathrm{a}}$ & $1,145 \pm 56$ & $1,112 \pm 60$ & $1,079 \pm 67^{\mathrm{a}}$ & $1,076 \pm 98^{\mathrm{a}}$ \\
\hline sKim-1 (pg/ml) & $518 \pm 67$ & $552 \pm 36$ & $530 \pm 38$ & $530 \pm 38$ & $410 \pm 31^{\mathrm{c}}$ & $401 \pm 33^{c}$ & $392 \pm 40^{c}$ & $390 \pm 42^{c}$ \\
\hline uNGAL (pg/ml) & $3,670 \pm 160$ & $3,687 \pm 139$ & $3,668 \pm 127$ & $3,690 \pm 145$ & $3,449 \pm 362^{c}$ & $3,318 \pm 303^{c}$ & $3,233 \pm 318^{c}$ & $3,131 \pm 339^{a, c}$ \\
\hline sNGAL (pg/ml) & $1,333 \pm 150$ & $1,709 \pm 147^{\mathrm{a}}$ & $1,650 \pm 120^{\mathrm{a}}$ & $1,562 \pm 120^{\mathrm{a}, \mathrm{b}}$ & $1,318 \pm 172$ & $1,302 \pm 144^{\mathrm{c}}$ & $1,296 \pm 123^{\mathrm{c}}$ & $1,310 \pm 115^{\mathrm{c}}$ \\
\hline $\mathrm{sCr}(\mu \mathrm{mol} / \mathrm{l})$ & $176 \pm 18$ & $185 \pm 15^{\mathrm{a}}$ & $201 \pm 35$ & $217 \pm 36^{\mathrm{a}, \mathrm{b}}$ & $170 \pm 24$ & $157 \pm 18^{c}$ & $116 \pm 17^{\mathrm{a}-\mathrm{c}}$ & $112 \pm 12^{\mathrm{a}-\mathrm{c}}$ \\
\hline
\end{tabular}

${ }^{\mathrm{a}} \mathrm{P}<0.05$ vs. $0 \mathrm{~h}$; ${ }^{\mathrm{b}} \mathrm{P}<0.05$ vs. $12 \mathrm{~h}$; ${ }^{\mathrm{C}}<0.05$ vs. group A. Group A, septic acute kidney injury with conventional drug treatment; group B, septic acute kidney injury with continuous renal replacement therapy; uKim-1, urinary kidney injury molecule 1; sKim-1, serum urinary kidney injury molecule 1; uNGAL, urinary neutrophil gelatinase-associated lipocalin; sNGAL, serum neutrophil gelatinase-associated lipocalin; sCr, serum creatinine. 


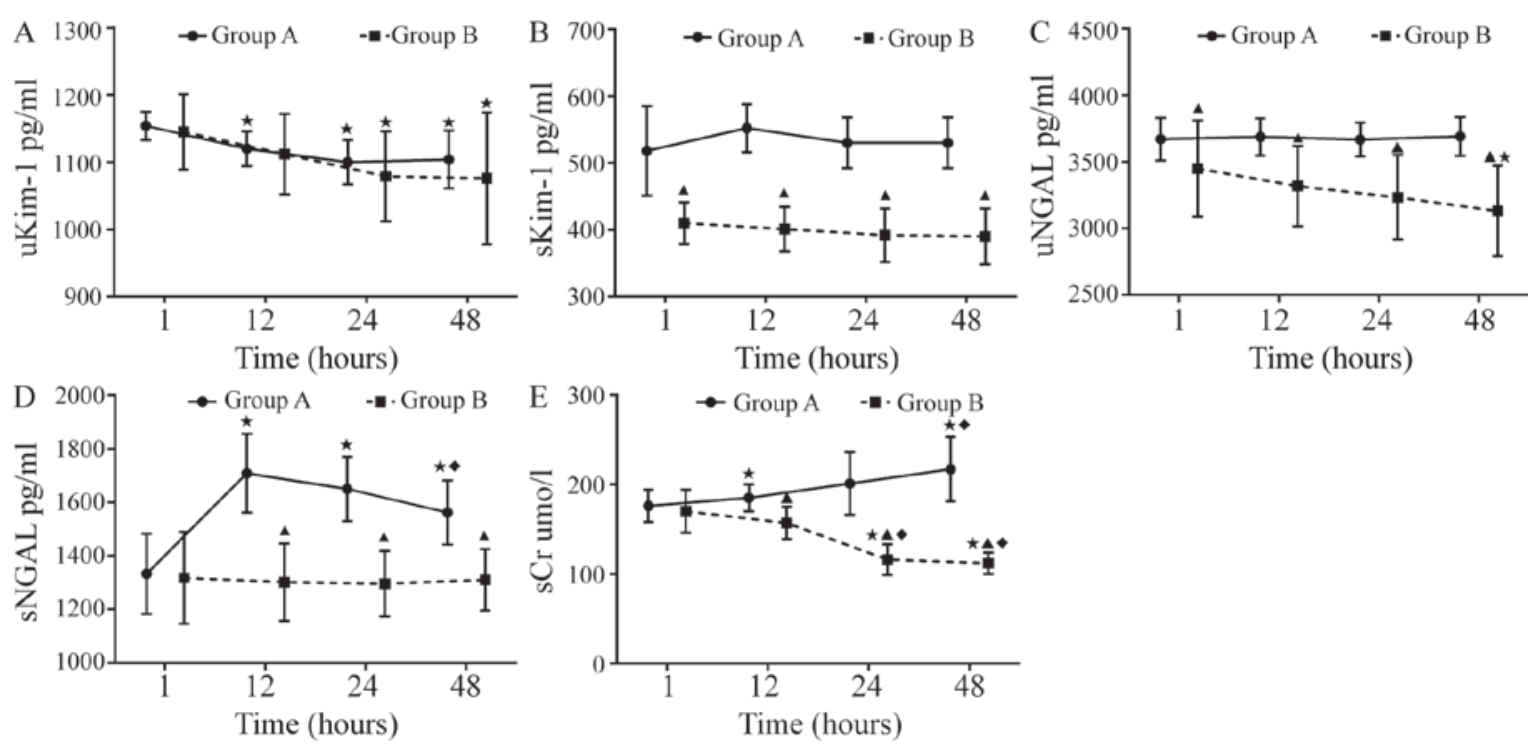

Figure 2. Levels of (A) uKim-1, (B) sKim-1, (C) uNGAL, (D) sNGAL and (E) sCr at various time points in patients with septic acute kidney injury. groups A and B. ${ }^{\wedge} \mathrm{P}<0.05$ vs. group $\mathrm{A} ;{ }^{\star} \mathrm{P}<0.05$ vs. $0 \mathrm{~h} ;{ }^{\bullet} \mathrm{P}<0.05$ vs. $12 \mathrm{~h}$. Group A, conventional drug treatment group; group B, continuous renal replacement therapy group; uKim-1, urinary kidney injury molecule 1 ; sKim-1, serum urinary kidney injury molecule 1; uNGAL, urinary neutrophil gelatinase-associated lipocalin; sNGAL, serum neutrophil gelatinase-associated lipocalin; sCr, serum creatinine.

Table IV. Sepsis biomarkers of sepsis before and after treatment.

\begin{tabular}{|c|c|c|c|c|c|c|c|c|}
\hline \multirow[b]{2}{*}{ Indication } & \multicolumn{4}{|c|}{ Group A $(n=17)$} & \multicolumn{4}{|c|}{ Group B $(n=21)$} \\
\hline & $0 \mathrm{~h}$ & $12 \mathrm{~h}$ & $24 \mathrm{~h}$ & $48 \mathrm{~h}$ & $0 \mathrm{~h}$ & $12 \mathrm{~h}$ & $24 \mathrm{~h}$ & $48 \mathrm{~h}$ \\
\hline $\mathrm{T}\left({ }^{\circ} \mathrm{C}\right)$ & $39.42 \pm 0.46$ & $39.24 \pm 0.29$ & $38.91 \pm 0.24^{\mathrm{a}, \mathrm{b}}$ & $38.81 \pm 0.19^{\mathrm{a}, \mathrm{b}}$ & $39.21 \pm 0.45$ & $38.82 \pm 0.21^{\mathrm{a}, \mathrm{c}}$ & $37.65 \pm 0.67^{\mathrm{a}-\mathrm{c}}$ & $37.30 \pm 0.41^{\mathrm{a}-\mathrm{c}}$ \\
\hline WBC $\left(\times 10^{9} / 1\right)$ & $14.84 \pm 3.22$ & $19.32 \pm 2.49^{\mathrm{a}}$ & $15.29 \pm 2.10^{b}$ & $15.53 \pm 1.93^{b}$ & $15.56 \pm 3.17$ & $14.50 \pm 2.34^{c}$ & $13.13 \pm 2.31^{\mathrm{a}, \mathrm{c}}$ & $12.53 \pm 2.49^{\mathrm{a}, \mathrm{c}}$ \\
\hline $\mathrm{NE}(\%)$ & $85.38 \pm 5.76$ & $89.19 \pm 3.56$ & $85.67 \pm 4.28$ & $87.66 \pm 2.81$ & $85.07 \pm 5.90$ & $84.65 \pm 5.37^{c}$ & $82.74 \pm 4.53^{c}$ & $78.67 \pm 3.81^{\mathrm{a}-\mathrm{c}}$ \\
\hline РCT (ng/ml) & $6.08 \pm 2.15$ & $6.44 \pm 2.18$ & $7.76 \pm 2.06$ & $8.18 \pm 2.10^{\mathrm{a}}$ & $6.12 \pm 2.08$ & $6.34 \pm 2.16$ & $4.53 \pm 1.70^{\mathrm{a}-\mathrm{c}}$ & $4.03 \pm 1.74^{\mathrm{a}-\mathrm{c}}$ \\
\hline $\mathrm{Lac}(\mathrm{mmol} / \mathrm{l})$ & $6.74 \pm 2.01$ & $8.05 \pm 1.47$ & $8.87 \pm 1.91^{\mathrm{a}}$ & $9.64 \pm 2.99^{\mathrm{a}}$ & $6.27 \pm 1.59$ & $6.15 \pm 1.47^{\mathrm{c}}$ & $3.90 \pm 1.30^{\mathrm{a}-\mathrm{c}}$ & $2.96 \pm 1.01^{\mathrm{a}-\mathrm{c}}$ \\
\hline $\begin{array}{l}\text { APACHE II } \\
\text { score }\end{array}$ & $13.89 \pm 2.03$ & $14.28 \pm 2.14$ & $16.28 \pm 1.60^{\mathrm{a}, \mathrm{b}}$ & $17.39 \pm 1.69^{\mathrm{a}, \mathrm{b}}$ & $14.86 \pm 1.81$ & $15.14 \pm 1.64$ & $12.95 \pm 1.96^{\mathrm{a}-\mathrm{c}}$ & $13.27 \pm 1.80^{\mathrm{a}-\mathrm{c}}$ \\
\hline
\end{tabular}

${ }^{\mathrm{a}} \mathrm{P}<0.05 \mathrm{vs} .0 \mathrm{~h} ;{ }^{\mathrm{b}} \mathrm{P}<0.05$ vs. $12 \mathrm{~h} ;{ }^{\mathrm{c}} \mathrm{P}<0.05$ vs. group A. Group A, septic acute kidney injury with conventional drug treatment; group B, septic acute kidney injury with continuous renal replacement therapy; T, body temperature; WBC, white blood cell count; NE, neutrophilic granulocyte ratio; PCT, procalcitonin; Lac, arterial blood lactic acid; APACHE II, acute physiology and chronicity health evaluation II.

that CRRT had a significant effect on the 28-day mortality of patients with septic AKI (group A vs. group B: 61.2 vs. 22.7\%, $\mathrm{P}=0.03$; Fig. 3).

Diagnostic value of uKim-1 and uNGAL. The cutoffs for AKI diagnosis were determined according to the Acute Kidney Injury Network diagnostic criteria ( $\mathrm{sCr}$ increase of $\geq 50 \%$ from baseline values), and a receiver-operator characteristic curve was constructed with the expression levels of uKim-1 and uNGAL, to evaluate the diagnostic value of uKim-1 and uNGAL in septic AKI patients (Fig. 4). The uKim-1 and uNGAL values suggested an improved performance when compared with the serum creatinine $(\mathrm{sCr})$ and blood urea nitrogen (BUN) levels (22) [area under the curve (AUC) 0.848 , $95 \%$ confidence interval (95\% CI) 0.731-0.965, and AUC
0.842, 95\% confidence interval, CI 0.713-0.970, respectively] for the diagnosis of septic AKI.

\section{Discussion}

Sepsis (1) is a SIRS caused by infection and can lead to severe sepsis, septic shock, and multiple organ dysfunction syndrome or even multi organ failure (MOF), a very serious medical condition. AKI is a common clinical syndrome that has been the focus of several recent studies $(9,23,24)$. Sepsis is considered one of the major reasons for AKI development in critically ill patients in the ICU. CRRT and particularly CVVH are widely used in ICU patients with septic AKI. Approximately $4 \%$ of patients treated in ICUs worldwide have AKI that mandates CRRT as a life-saving measure (25). 


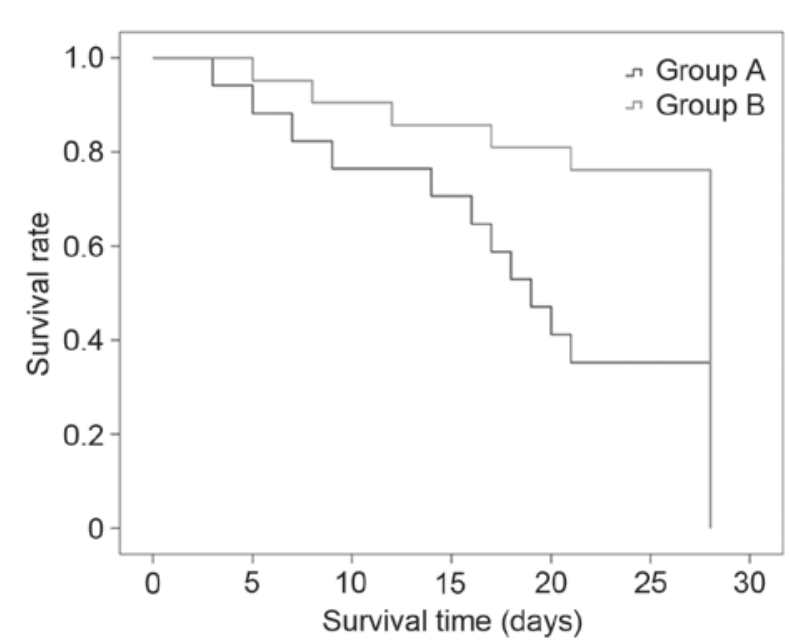

Figure 3. 28-day survival curves of the patients with septic acute kidney injury. Group A vs. group B (61.2 vs. 22.7\%; $\mathrm{P}=0.03$ ). Group A, conventional drug treatment group; group B, continuous renal replacement therapy group.

Although supportive care with CRRT has been the mainstay of treatment of septic AKI for more than five decades, many fundamental aspects of CRRT management remain controversial, including selection of modality, timing of initiation, dosing of therapy, efficacy evaluation, and its mechanism of action. The possible reason for this is that the $\mathrm{sCr}$ level has been the only detectable marker used to reflect the change of renal function during CRRT and to evaluate the therapeutic effectiveness of the method. Firstly, $\mathrm{sCr}$ does not accurately reflect the glomerular filtration rate in patients, particularly those with septic AKI, who are not in a stable condition; $\mathrm{sCr}$ may be low in the early stages of severe AKI (26). Secondly, dialysis may reduce $\mathrm{sCr}$ levels. Therefore, the assessment of kidney function by measuring the $\mathrm{sCr}$ level once dialysis is initiated may not be accurate (27).

Kim-1 is a glycoprotein that is expressed in proximal renal tubular epithelial cells in response to cellular injury (28). In hospitalized patients with AKI, urinary Kim-1 has been shown to predict adverse clinical outcomes such as mortality (29). NGAL is a $25-\mathrm{kDa}$ protein originally isolated from neutrophil secondary granules (30) and is a classic biomarker for the early diagnosis and short-term outcome of AKI. Therefore, in the present study, Kim-1 and NGAL were selected for use in the evaluation of the therapeutic effectiveness of CRRT in septic AKI and investigation of the possible mechanisms.

The aim of the present study was to investigate the change in the levels of Kim-1 before and after treatment. In contrast to previous studies, it was initially found that the levels of sKim-1 in septic AKI patients were significantly higher than those in normal persons. However, our results are in accordance with previous results (31). Kim-1 is a member of the immunoglobulin family and is expressed in the surface of activated $\mathrm{T}$ cells $\left(\mathrm{CD} 4^{+} \mathrm{Th} 2\right)$ (32); therefore, sKim-1 may be involved in the immune response to sepsis and its level is higher than normal in this condition. Previous animal and clinical studies have demonstrated $(33,34)$ that Kim-1 is an inflammation mediator associated with the pathogenesis of asthma and rheumatoid arthritis. A prospective, multicenter cohort study (35) found that Kim-1 peaked at 2 days after cardiac surgery in adults

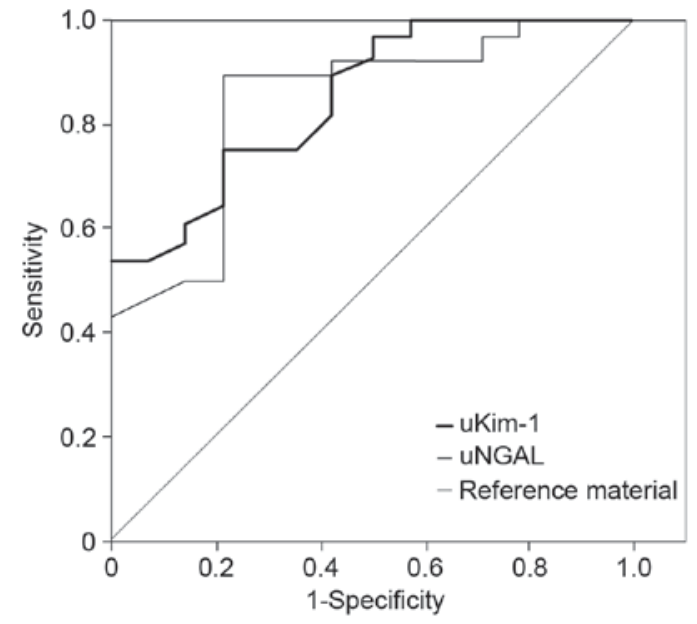

Figure 4. Receiver operating curve for uKim-1 and uNGAL. uKim-1, urinary kidney injury molecule 1; uNGAL, urinary neutrophil gelatinase-associated lipocalin.

and at 1 day after surgery in children, and that the elevations of Kim-1 were associated with AKI and adverse outcomes in adults.

In group B, 21 patients completed the study. uKim-1 showed a gradually declining trend after CRRT at 24 and $48 \mathrm{~h}$; and in group A, it declined at 12,24 , and $48 \mathrm{~h}$ after treatment; however, the trend of decline in group B was notably faster compared with group A. The results suggest that conventional antisepsis therapy reduced uKim-1 at a slower rate than CRRT, whereas CRRT could continue to reduce uKim-1 while improving renal function sustainably ( $\geq 48 \mathrm{~h}$ ). To the best of our knowledge, the present study was also the first to find that Kim-1 was not present in the ultrafiltrate of CRRT. Moreover, sKim-1 exhibited no significant change before and after CRRT, suggesting that sKim-1 had not been cleared by CRRT. Accordingly, it was presumed that CRRT improved and promoted renal tubular function and did not clear sKim-1 directly to reduce uKim-1; moreover, the process of AKI has been inhibited at the early stage. In addition, uKim-1 exhibited an improved performance compared with $\mathrm{sCr}$ and Urine Output (AUC 0.848, 95\% CI 0.731-0.965); thus, uKim-1 could be used to reflect the change of renal function during CRRT and evaluate the therapeutic effectiveness of the method.

Concerning the change in the levels of NGAL before and after treatment, in groups A and B, the expression levels of sNGAL were significantly higher compared with those in group C. It was found that SNGAL was significantly increased at 12, 24 and $48 \mathrm{~h}$ after treatment compared with the level prior to treatment in group A, whereas it was maintained at a stable level in group B. This result suggested that the study sample requires a different experimental design. However, it also suggested that the current standard antisepsis treatment programs were not effective in the early stage of sepsis (at least within $48 \mathrm{~h}$ ) and were not able to reverse the process of AKI, whereas early and timely intervention with CRRT could maintain sNGAL at a stable level. NGAL is synthesized in the bone during the late immature stage in young and mature marrow neutrophils, and is involved in the inflammatory response to sepsis. Bagshaw et al (36) found that patients with septic AKI have higher detectable plasma and urine NGAL levels 
compared with nonseptic AKI patients. These differences in NGAL values in septic AKI may have diagnostic and clinical relevance and pathogenetic implications. Chakraborty et al (37) found sufficient evidence, from multi-institutional randomized trials, suggesting the potential of NGAL as an early biomarker for severe acute pancreatitis (SAP), and indicating that high NGAL levels predict MOF and fatal outcome in patients with SAP. In the present study, in group A, sNGAL showed a continuous upward trend because of failure to block the inflammatory response and reduce the release of inflammatory factors. However, in group B, owing to the clearance of inflammatory mediators and reduction of the inflammatory response by timely CRRT, there was no significant change.

uNGAL was maintained at a high level and did not change significantly in group A prior to and following treatment, whereas it showed a stepwise downward trend at 24 and $48 \mathrm{~h}$ after CRRT in group B. The levels of sNGAL and $\mathrm{UNGAL}$ in group B were decreased significantly at 12 , 24 and 48 h compared with those in group A. NGAL was not detected in the ultrafiltrate of CRRT. This result was consistent with the study by de Geus et al (38), which found that sNGAL was not cleared by CRRT filtration. Together with the trend of sNGAL change, the result suggested that sNGAL was not cleared by CRRT. Accordingly, it may be presumed that CRRT is able to improve and promote renal tubular function, but may not eliminate sNGAL directly to reduce uNGAL levels, and that the process of AKI has been inhibited at the early stage. UNGAL was superior to sCr and UO (39) (AUC 0.842, 95\% CI 0.713-0.970) for the diagnosis of septic AKI. uNGAL is highly sensitive predictor of AKI and death in septic patients admitted into emergency rooms (40). Therefore, uNGAL could be used to reflect the change of renal function during CRRT and evaluate the therapeutic effectiveness of the method.

The present study also aimed to evaluate the prognosis of septic AKI patients. The morbidity and mortality of septic AKI vary largely among reports from different countries or districts. One study showed that the mortality rate of patients with septic shock was $43 \%$; however, when associated with AKI, the fatality rate increased to $86 \%$ (41). In the present study, the 28-day mortality of septic AKI was $61.1 \%$, which is consistent with other reports (42-44).

In group $\mathrm{B}, \mathrm{WBC}, \mathrm{NE}, \mathrm{Lac}, \mathrm{PCT}$ and APACHE II score were significantly decreased following treatment, whereas group A did not show changes in these parameters. This suggests that the infection condition of patients with septic AKI was improved in group B, and that CRRT controlled infection better than did conventional treatment. The 28-day mortality rate of group B was significantly lower than that of group A (22.7 vs. 61.1\%), which is consistent with the report that early CRRT can significantly reduce the mortality of patients with septic AKI (45).

The pathogenesis of septic AKI predominantly involves toxic and immune-mediated mechanisms. Sepsis causes the release of numerous pro-inflammatory and anti-inflammatory mediators (such as cytokines, arachidonic acid metabolites, and thrombogenic agents) that may contribute to the development of AKI (46). Studies have found evidence of renal tubular cell apoptosis in response to inflammatory mediators in endoxemia $(47,48)$. A more prominent role of apoptosis rather than pure necrosis has been indicated in the pathophysiology of sepsis and septic shock (49). In a previous study, apoptosis was proposed as a major factor in septic AKI (20) and acute tubular apoptosis was demonstrated in patients with septic AKI, whereas almost no apoptosis was detected in the non-septic AKI patients. Animal studies $(50,51)$ have confirmed that apoptosis, renal ischemia/reperfusion injury, calcium overload and intracellular cytokines (IL-6, IL-1, tumor necrosis factor) and caspase participate in septic AKI.

In the present study, it was found that CRRT reduced the expression levels of uKim-1 and UNGAL; however, it had little effect on sKim-1 and sNGAL levels. Shen et al (52) found that the serum and myocardial concentrations of IL- $1 \beta$ and IL- 6 , and the myocardial mRNA expression of IL-6 decreased significantly following a combination treatment with CRRT in a piglet model. Therefore, it is hypothesized the possible mechanisms of CRRT are clearance of pro-inflammatory mediators, reduction of vascular endothelial cell injury, improvement of renal perfusion, reduction of the infiltration of inflammatory cells and promotion of the recovery of renal tubular function, which improve the prognosis of septic AKI. Early, sustained and effective intervention with CRRT in patients with septic $\mathrm{AKI}$ is important in improving prognosis.

Concerning the changes in the levels of $\mathrm{sCr}$ before and after treatment, in the present study, a gradual upward trend in $\mathrm{sCr}$ was observed after treatment in group A; however, in group B, sCr gradually decreased after CRRT, and was significantly lower compared with that in group A. In an animal model (53), it was found that serious infections reduced the production of $\mathrm{sCr}$ in septic mice whose kidneys had been removed, showing that $\mathrm{sCr}$ did not accurately reflect the change of renal function in patients with septic AKI who require CRRT.

The present study has several limitations. First, the study sample was relatively small, which may have influenced the reliability of the results for changes of Kim-1 and NGAL levels after CRRT treatment. Second, an in-depth analysis on the possible mechanisms of CRRT was not performed. Therefore, it is suggested that a large multicenter prospective randomized controlled trial should be carried out in combination with animal experiments to more deeply investigate the mechanisms of CRRT and confirm the findings of the current study.

In conclusion, in this study, uKim-1 and uNGAL were decreased significantly following CRRT, but there were no evident effects on sKim-1 and sNGAL. Moreover, Kim-1 and NGAL were not detected in the ultrafiltrate of CRRT. As reliable biomarkers, uKim-1 and uNGAL can reflect the renal injury state earlier compared with sCr and UO (39) and may be used to reflect the change of renal function during CRRT and evaluate the therapeutic effectiveness of the method. These results imply that CRRT may improve kidney function by eliminating inflammatory mediators from the blood and reducing the expression levels of uKim-1 and uNGAL.

\section{Acknowledgements}

This study was supported by Guangdong Province Science and Technology Social Development Projects (2013B021800075) and Zhanjiang Financial Fund Allocated for Competitive Scientific and Technological Projects (2012C0302-46). 


\section{References}

1. Piccinni P, Cruz DN, Gramaticopolo S, Garzotto F, Dal Santo M, Aneloni G, Rocco M, Alessandri E, Giunta F, Michetti V, et al: Prospective multicenter study on epidemiology of acute kidney injury in the ICU: A critical care nephrology Italian collaborative effort (NEFROINT). Minerva Anestesiol 77: 1072-1083, 2011.

2. Oppert M, Engel C, Brunkhorst FM, Bogatsch H, Reinhart K, Frei U, Eckardt KU, Loeffler M and John S; German Competence Network Sepsis (Sepnet): Acute renal failure in patients with severe sepsis and septic shock a significant independent risk factor for mortality: Results from the German Prevalence Study. Nephrol Dial Transplant 23: 904-909, 2008.

3. Thakar CV, Christianson A, Freyberg R, Almenoff P and Render ML: Incidence and outcomes of acute kidney injury in intensive care units: A Veterans Administration study. Crit Care Med 37: 2552-2558, 2009.

4. Kai K, Yamaguchi T, Yoshimatsu Y, Kinoshita J, Teranishi M and Takasaki W: Neutrophil gelatinase-associated lipocalin, a sensitive urinary biomarker of acute kidney injury in dogs receiving gentamicin. J Toxicol Sci 38: 269-277, 2013.

5. Katagiri D, Doi K, Matsubara T, Negishi K, Hamasaki Y, Nakamura K, Ishii T, Yahagi N and Noiri E: New biomarker panel of plasma neutrophil gelatinase-associated lipocalin and endotoxin activity assay for detecting sepsis in acute kidney injury. J Crit Care 28: 564-570, 2013.

6. Sinha V, Vence LM and Salahudeen AK: Urinary tubular protein-based biomarkers in the rodent model of cisplatin nephrotoxicity: A comparative analysis of serum creatinine, renal histology, and urinary KIM-1, NGAL and NAG in the initiation, maintenance, and recovery phases of acute kidney injury. J Investig Med 61: 564-568, 2013.

7. Buelow MW, Dall A, Regner K, Weinberg C, Bartz PJ, Sowinski J, Rudd N, Katzmark L, Tweddell JS and Earing MG: Urinary interleukin-18 and urinary neutrophil gelatinase-associated lipocalin predict acute kidney injury following pulmonary valve replacement prior to serum creatinine. Congenit Heart Dis 7: 441-447, 2012.

8. Park MY, Choi SJ, Kim JK, Hwang SD and Lee YW: Urinary cystatin $\mathrm{C}$ levels as a diagnostic and prognostic biomarker in patients with acute kidney injury. Nephrology (Carlton) 18: 256-262, 2013

9. Xie Y, Wang Q, Wang C, Qi C, Ni Z and Mou S: High urinary excretion of kidney injury molecule-1 predicts adverse outcomes in acute kidney injury: A case control study. Crit Care 20: 286 , 2016.

10. Shao X, Tian L, Xu W, Zhang Z, Wang C, Qi C, Ni Z and Mou S: Diagnostic value of urinary kidney injury molecule 1 for acute kidney injury: A meta-analysis. PLoS One 9: e84131, 2014.

11. Au V, Feit J, Barasch J, Sladen RN and Wagener G: Urinary neutrophil gelatinase-associated lipocalin (NGAL) distinguishes sustained from transient acute kidney injury after general surgery. Kidney Int Rep 1: 3-9, 2016.

12. Wagener G, Minhaz M, Mattis FA, Kim M, Emond JC and Lee HT: Urinary neutrophil gelatinase-associated lipocalin as a marker of acute kidney injury after orthotopic liver transplantation. Nephrol Dial Transplant 26: 1717-1723, 2011.

13. Liebetrau C, Dörr O, Baumgarten H, Gaede L, Szardien S, Blumenstein J, Rolf A, Möllmann H, Hamm C, Walther T, et al: Neutrophil gelatinase-associated lipocalin (NGAL) for the early detection of cardiac surgery associated acute kidney injury. Scand J Clin Lab Invest 73: 392-399, 2013.

14. Liangos O, Tighiouart H, Perianayagam MC, Kolyada A, Han WK, Wald R, Bonventre JV and Jaber BL: Comparative analysis of urinary biomarkers for early detection of acute kidney injury following cardiopulmonary bypass. Biomarkers 14 423-431, 2009.

15. Huang Y and Don-Wauchope AC: The clinical utility of kidney injury molecule 1 in the prediction, diagnosis and prognosis of acute kidney injury: A systematic review. Inflamm Allergy Drug Targets 10: 260-271, 2011.

16. Rahimzadeh N, Otukesh H, Hoseini R, Sorkhi H, Otukesh M, Hoseini S and Torkzaban M: Are serum and urine neutrophil gelatinase-associated lipocalin predictive of renal graft function in short term? Pediatr Transplant 16: 796-802, 2012.

17. Dellinger RP, Levy MM, Rhodes A, Annane D, Gerlach H, Opal SM, Sevransky JE, Sprung CL, Douglas IS, Jaeschke R, et al: Surviving sepsis campaign: International guidelines for management of severe sepsis and septic shock: 2012. Crit Care Med 41: 580-637, 2013.
18. Levy MM, Fink MP, Marshall JC, Abraham E, Angus D, Cook D, Cohen J, Opal SM, Vincent JL and Ramsay G; International Sepsis Definitions Conference: 2001 SCCM/ESICM/ACCP/ATS/SIS International sepsis definitions conference. Intensive Care Med 29: 530-538, 2003.

19. Mehta RL, Kellum JA, Shah SV, Molitoris BA, Ronco C, Warnock DG and Levin A; Acute Kidney Injury Network: Report of an initiative to improve outcomes in acute kidney injury. Crit Care 11: R31, 2007.

20. Lerolle N, Nochy D, Guérot E, Bruneval P, Fagon JY, Diehl JL and Hill G: Histopathology of septic shock induced acute kidney injury: Apoptosis and leukocytic infiltration. Intensive Care Med 36: 471-478, 2010

21. Knaus WA, Draper EA, Wagner DP and Zimmerman JE: APACHE II: A severity of disease classification system. Crit Care Med 13: 818-829, 1985.

22. Luo QH, Chen ML, Chen ZL, Huang C, Cheng AC, Fang J, Tang L and Geng Y: Evaluation of KIM-1 and NGAL as early indicators for assessment of gentamycin-induced nephrotoxicity in vivo and in vitro. Kidney Blood Press Res 41: 911-918, 2016.

23. Srisawat N and Kellum JA: Acute kidney injury: Definition, epidemiology, and outcome. Curr Opin Crit Care 17: 548-555, 2011.

24. Doi K: Kidney-heart interactions in acute kidney injury. Nephron 134: 141-144, 2016.

25. Walcher A, Faubel S, Keniston A and Dennen P: In critically ill patients requiring CRRT, AKI is associated with increased respiratory failure and death versus ESRD. Ren Fail 33: 935-942, 2011.

26. Delanaye P, Cavalier E, Morel J, Mehdi M, Maillard N, Claisse G, Lambermont B, Dubois BE, Damas P, Krzesinski JM, et al: Detection of decreased glomerular filtration rate in intensive care units: Serum cystatin C versus serum creatinine. BMC Nephrol 15: 9, 2014

27. Zhou Y, Tang Z, Liu ZH and Li LS: Acute lymphoblastic leukemia complicated by acute renal failure: A case report and review of the literature. Clin Nephrol 73: 321-325, 2010.

28. Kirk R: Renal fibrosis: KIM-1 expression links kidney injury with CKD in mice. Nat Rev Nephrol 9: 627, 2013.

29. Tu Y, Wang H, Sun R, Ni Y, Ma L, Xv F, Hu X, Jiang L, Wu A, Chen X, et al: Urinary netrin-1 and KIM-1 as early biomarkers for septic acute kidney injury. Ren Fail 36: 1559-1563, 2014.

30. Valette X, Savary B, Nowoczyn M, Daubin C, Pottier V, Terzi N, Seguin A, Fradin S, Charbonneau P, Hanouz JL and du Cheyron D: Accuracy of plasma neutrophil gelatinase-associated lipocalin in the early diagnosis of contrast-induced acute kidney injury in critical illness. Intensive Care Med 39: 857-865, 2013.

31. Boli Ren: The protection of low molecular heparin in the rat which sepsis induced acute kidney injury. Dissertation, The emergency medicine teaching and research section in second military medical university of Shanghai, 2010.

32. Nozaki Y, Nikolic-Paterson DJ, Snelgrove SL, Akiba H, Yagita H, Holdsworth SR and Kitching AR: Endogenous Tim-1 (Kim-1) promotes T-cell responses and cell-mediated injury in experimental crescentic glomerulonephritis. Kidney Int 81: 844-855, 2012

33. Sonar SS, Hsu YM, Conrad ML, Majeau GR, Kilic A, Garber E, Gao Y, Nwankwo C, Willer G, Dudda JC, et al: Antagonism of TIM-1 blocks the development of disease in a humanized mouse model of allergic asthma. J Clin Invest 120: 2767-2781, 2010.

34. Shah N, Mohamed FE, Jover-Cobos M, Macnaughtan J, Davies N, Moreau R, Paradis V, Moore K, Mookerjee R and Jalan R: Increased renal expression and urinary excretion of TLR4 in acute kidney injury associated with cirrhosis. Liver Int 33: 398-409, 2013.

35. Parikh CR, Thiessen-Philbrook H, Garg AX, Kadiyala D, Shlipak MG, Koyner JL, Edelstein CL, Devarajan P, Patel UD, Zappitelli M, et al: Performance of kidney injury molecule-1 and liver fatty acid-binding protein and combined biomarkers of AKI after cardiac surgery. Clin J Am Soc Nephrol 8: 1079-1088, 2013.

36. Bagshaw SM, Bennett M, Haase M, Haase-Fielitz A, Egi M, Morimatsu H, D'amico G, Goldsmith D, Devarajan P and Bellomo R: Plasma and urine neutrophil gelatinase-associated lipocalin in septic versus non-septic acute kidney injury in critical illness. Intensive Care Med 36: 452-461, 2010.

37. Chakraborty S, Kaur S, Muddana V, Sharma N, Wittel UA, Papachristou GI, Whitcomb D, Brand RE and Batra SK: Elevated serum neutrophil gelatinase-associated lipocalin is an early predictor of severity and outcome in acute pancreatitis. Am J Gastroenterol 105: 2050-2059, 2010 
38. de Geus HR, Betjes MG and Bakker J: Neutrophil gelatinase-associated lipocalin clearance during veno-venous continuous renal replacement therapy in critically ill patients. Intensive Care Med 36: 2156-2157, 2010

39. Nga HS, Medeiros P, Menezes P, Bridi R, Balbi A and Ponce D: Sepsis and AKI in clinical emergency room patients: The role of urinary NGAL. Biomed Res Int 2015: 413751, 2015.

40. Liu WL, Wang JY, Huang TM, Lai CC, Wang CY, Yeh YC, Chou A, Chu TS, Lin YF, Chiu JS, et al: Hospital mortality of septic acute kidney injury requiring renal replacement therapy in the postoperative elderly. Int J Gerontol 6: 75-79, 2012.

41. Bunz H, Weyrich P, Peter A, Baumann D, Tschritter O, Guthoff M, Beck R, Jahn G, Artunc F, Häring HU, et al: Urinary neutrophil gelatinase-associated lipocalin (NGAL) and proteinuria predict severity of acute kidney injury in Puumala virus infection. BMC Infect Dis 15: 464, 2015.

42. Singbartl K and Kellum JA: AKI in the ICU: Definition, epidemiology, risk stratification, and outcomes. Kidney Int 81: 819-825. 2012

43. Barbar SD, Binquet $\mathrm{C}$, Monchi M, Bruyère R and Quenot JP: Impact on mortality of the timing of renal replacement therapy in patients with severe acute kidney injury in septic shock: The IDEAL-ICU study (initiation of dialysis early versus delayed in the intensive care unit): Study protocol for a randomized controlled trial. Trials 15: 270, 2014.

44. Doyle JF and Forni LG: Update on sepsis-associated acute kidney injury: Emerging targeted therapies. Biologics 10: 149-156, 2016.

45. Oh HJ, Shin DH, Lee MJ, Koo HM, Doh FM, Kim HR, Han JH, Park JT, Han SH, Yoo TH, et al: Early initiation of continuous renal replacement therapy improves patient survival in severe progressive septic acute kidney injury. J Crit Care 27: 743.e9-18, 2012.
46. Murugan R, Karajala-Subramanyam V, Lee M, Yende S, Kong L, Carter M, Angus DC and Kellum JA; Genetic and Inflammatory Markers of Sepsis (GenIMS) Investigators: Acute kidney injury in non-severe pneumonia is associated with an increased immune response and lower survival. Kidney Int 77: 527-535, 2010.

47. Payen D, Lukaszewicz AC, Legrand M, Gayat E, Faivre V, Megarbane B, Azoulay E, Fieux F, Charron D, Loiseau P and Busson M: A multicentre study of acute kidney injury in severe sepsis and septic shock: Association with inflammatory phenotype and HLA genotype. PLoS One 7: e35838, 2012.

48. Angus DC and van der Poll T: Severe sepsis and septic shock. N Engl J Med 369: 840-851, 2013.

49. De Kock I, Van Daele C and Poelaert J: Sepsis and septic shock: Pathophysiological and cardiovascular background as basis for therapy. Acta Clin Belg 65: 323-329, 2010.

50. Gomez H, Ince C, De Backer D, Pickkers P, Payen D, Hotchkiss J and Kellum JA: A unified theory of sepsis-induced acute kidney injury: Inflammation, microcirculatory dysfunction, bioenergetics, and the tubular cell adaptation to injury. Shock 41: 3-11, 2014 .

51. Le Dorze M, Legrand M, Payen D and Ince C: The role of the microcirculation in acute kidney injury. Curr Opin Crit Care 15: 503-508, 2009.

52. Shen J, Yu W, Chen Q, Shi J, Hu Y, Zhang J, Gao T, Xi F, He C, Gong J, et al: Continuous renal replacement therapy (CRRT) attenuates myocardial inflammation and mitochondrial injury induced by veno-venous extracorporeal membrane oxygenation (VV ECMO) in a healthy piglet model. Inflammation 36: 1186-1193, 2013.

53. Doi K, Yuen PS, Eisner C, Hu X,Leelahavanichkul A, Schnermann J and Star RA: Reduced production of creatinine limits its use as marker of kidney injury in sepsis. J Am Soc Nephrol 20: 1217-1221, 2009. 